Research Article

\title{
Fingerprint Spectrophotometric Methods for the Determination of Co-Formulated Otic Solution of Ciprofloxacin and Fluocinolone Acetonide in Their Challengeable Ratio
}

\author{
Reem H. Obaydo (iD) and Amir Alhaj Sakur \\ Analytical and Food Chemistry Department, Faculty of Pharmacy, Aleppo University, Aleppo, Syria \\ Correspondence should be addressed to Reem H. Obaydo; obaydo.reem@gmail.com
}

Received 2 March 2019; Accepted 18 July 2019; Published 8 September 2019

Academic Editor: Antonio V. Herrera-Herrera

Copyright ( 2019 Reem H. Obaydo and Amir Alhaj Sakur. This is an open access article distributed under the Creative Commons Attribution License, which permits unrestricted use, distribution, and reproduction in any medium, provided the original work is properly cited.

\begin{abstract}
Six spectrophotometric methods were developed to determine a new single-dose otic solution known as "Otovel ${ }^{\circledR}$," which consists of two components: the major one is ciprofloxacin (CIP) and the minor is fluocinolone acetonide (FLU). The ratio of (CIP) and (FLU) in Otovel ${ }^{\circledR}$ is $12: 1$, which is considered a challengeable ratio for UV determination. Thus, spectrum addition as a sample enrichment technique was required for the analysis of (FLU) low concentration. All these methods were capable of resolving the spectra for each component in $D^{0}$ belonging to the fingerprint resolution technique. The former absorptivity centering (a-centering) method was recently developed in 2018; it was effectively applied for its solution of both binary components in Otovel ${ }^{\circledR}$, while another method, ratio subtraction (RS), is considered as an original resolution method that could be applied to determine only one component in mixtures. However, the other four methods that are related to their original method (RS) were extended ratio subtraction (EXRS), constant multiplication (CM), unified constant subtraction (UCS), and spectrum subtraction (SS). They were also easily applied for completing the quantification of binary mixture drugs present in Otovel ${ }^{\circledR}$. The linearity ranges were found to be $3.0-15.0 \mu \mathrm{g} / \mathrm{mL}$ for (CIP) and (FLU), respectively. All results acquired from the proposed methods were successfully estimated according to ICH criteria and were statistically compared with official ones where no differences were noticed.
\end{abstract}

\section{Introduction}

Recently many pharmaceutical companies have provided a fixed-dose combination instead of monotherapy for the treatment of certain diseases, offering more competence and less cost and decreasing the side effects associated with the treatment.

Otovel $^{\circledR}$ is considered an example of fixed-dose antibioticcorticosteroid combination otic drops, which has been recently approved by the FDA for otorrhea treatment [1]. Various studies have reported that the topical antibioticcorticosteroid drops are more effective in therapy than both antibiotic alone and glucocorticoid treatment on its own $[2,3]$.

Ciprofloxacin and fluocinolone acetonide have been recently co-formulated in Otovel ${ }^{\circledR}$ otic solution; the ratio of the two proposed drugs is $12: 1$, respectively. This ratio limits the analysis of this preparation; thus, spectrum addition technique [4] was applied to increase and determine the amount of fluocinolone acetonide.

Ciprofloxacin hydrochloride (CIP) belongs to a class of drugs called quinolone antibiotics that work by stopping the growth of bacteria. Fluocinolone acetonide (FLU) is a medium-strength corticosteroid, which has anti-inflammatory, antipruritic, and vasoconstrictive properties [5-7]. The structures are shown in Figure 1.

Literature survey revealed that (CIP) has been determined as a single component using spectrophotometry [8-10], thin layer chromatography $[11,12]$, HPLC $[13,14]$, capillary electrophoresis $[15,16]$, and chemometric method $[17,18]$. Estimation of (FLU) as single formulation was accomplished using spectrophotometry [19], gas chromatography [20], thin layer chromatography [21], and HPLC [22-27]. 




(a)

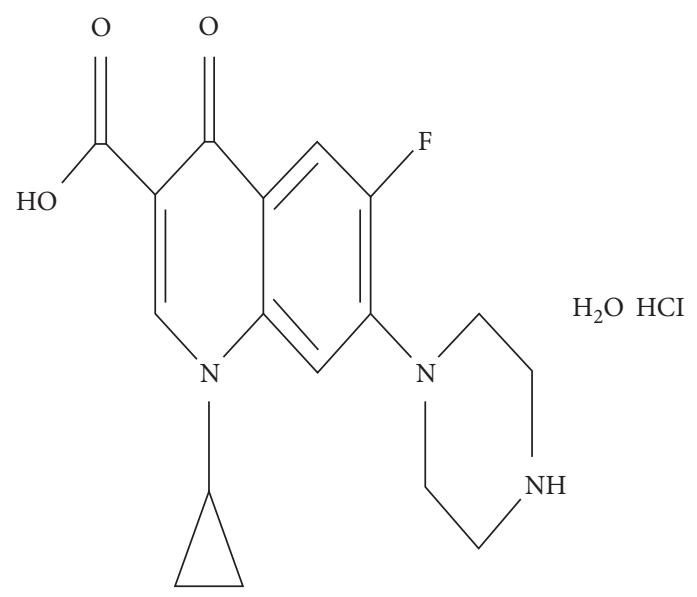

(b)

Figure 1: Chemical structure of fluocinolone acetonide (a) and ciprofloxacin hydrochloride monohydrate (b).

Recently, the literature reports only one study for the concurrent determination of (CIP) and (FLU) in Otovel $^{\circledR}$ by the same authors of the present work. In the study [28], spectrophotometric methods depending on presence of isosbestic points have been implemented for the simultaneous determination of both drugs in Otovel ${ }^{\circledR}$. However, dealing with isosbestic-point spectrophotometric methods requires two regression equations at least to complete the analysis. But, these isosbestic-point spectrophotometric techniques could not achieve the resolution of the spectra with multicomponent mixtures in zero-order form, and as a result, this technique could not be used to get the resolved spectral profile for each component in mixtures.

Spectrophotometric methods based on isosbestic point (in zero order, ratio, or derivative) for resolving binary mixtures with minor components required derivative steps, calculating the area under the curve, and obtaining ratio spectra, and this makes these methods need multiple steps to accomplish the analysis of the coformulated drugs.

The reported methods in [28] are based on leveling effect of the isoabsorptive point in binary mixture with minor component. All methods require presence of isoabsorptive point in spectra as well as the concentration of the minor component calculated based on the difference between the total concentration and the concentration of the major one, and thus, making any mistake in the determination of the total concentration and the major one reflects on the determination of the minor component. So, the reported work fails to give a special regression equation for determination the minor component and its concentration was calculated by difference between the total concentration and the major one.

The determination and analysis of co-formulated drug mixtures is a daily challenge for drug analysts. Academic researchers in the analytical field must deal with new proposals to solve several problems faced by analysts.

Through this investigation, the fingerprint resolution techniques were suggested to get more accurate results for the determination of minor component (FLU) presenting in the binary mixture of Otovel ${ }^{\circledR}$. In addition, the novel factorized spectrum was also suggested to be used as an innovative resolution tool for analysis of mixtures.

These methods were based on utilizing the absorptivity factor or constants of the ratio spectra which eliminate the spectral overlapping without prior separation and do not require search for zero-crossing points.

In terms of quality control and for all quantitative analysis, peak purity is a major task, which can be adopted in different ways; the fingerprint resolution techniques are one of the most important approaches which is used in quality control laboratories. An essential requisite of these techniques is the ability to get the recovered zero-order absorption spectrum of each drug separately from the mixture of the drugs with overlapped spectra, and as a result, the purity of the separated spectra could be verified. The advantage of using the fingerprint resolution technique is the ability to determine each component in the mixture in the zero-order spectra at $\lambda_{\max }$ with maximum accuracy and precision.

The spectrophotometric methods which belong to the fingerprint resolution technique were as follows: the absorptivity centering (a-centering) method [29-31], which was recently published in 2018, and ratio subtraction method (RS) [32-34]. The latter method (RS) was also used with extended ratio subtraction (EXRS) $[35,36]$, constant multiplication (CM) $[37,38]$, unified constant subtraction (UCS) [39], and spectrum subtraction (SS) $[40,41]$ methods to complete the resolution technique.

For best pharmacological action, (CIP) and (FLU) were prepared in their co-formulated otic solution in ratio $12: 1$, respectively. This study aims to apply the six spectrophotometric methods among the fingerprint resolution technique for determination of (CIP) and (FLU) in their challengeable ratio. The recovered zero-order spectra of the cited drugs confirmed their purity. Also statistically, studies were accomplished amongst the presented methods and the 
official ones, and insignificant differences were remarked. The proposed methods were validated in relation to International Conference on Harmonization (ICH) guidelines [42]. These presented methods could be investigated in quality control laboratories lacking HPLC instruments using the built-in spectrophotometer software without any need for purchasing special software.

\section{Theoretical Background}

2.1. Absorptivity Centering (a-Centering) Method. This technique can resolve the mixture of a binary drug $(X+Y)$ which has shown partially overlapping spectra and interfered at a specific isoabsorptive point $\lambda_{\text {iso }}$. It also depends on the choice of two special wavelengths. The first one is $\lambda_{\text {iso }}$ and the second one is $\lambda_{2}$ at which the spectrum $Y$ is more continuous than the spectrum $X$ and the spectrum $X$ appears to have no intersection with spectrum $Y$ at these $\lambda_{2}$ selected wavelengths.

Before applying this method, some spectral calculation and regression equations should be done, as follows:

Absorptivity inverse $\left(1 / a_{\lambda \text { iso }}\right)$ at $\lambda_{\text {iso }}$ is calculated by applying one of the following software:

(1) Microsoft Excel software:

Absorbance at $\lambda_{\text {iso }}$ for different concentrations of pure $X$ or $Y$ was measured, and then, each absorbance is divided by its concentration to obtain its correlated absorptivity $\left(a_{\lambda \text { iso }}\right)$; consequently, the means of the obtained values and their inverse (1/ $\left.a_{\lambda \text { iso }}\right)$ are calculated as follows:

$$
a_{\lambda \text { iso }}=\frac{A_{(\lambda \mathrm{iso})}}{\text { conc. }}
$$

(2) Spectrophotometer software:

The ratio spectra of pure $Y$ are obtained by dividing different concentrations of $Y$ spectra by the $Y$ normalized spectrum of $Y$, and then, a response correlation value $(\mathrm{RCV})$ is calculated at $\lambda_{\text {iso }}$ which is a constant value representing $\left[\mathrm{P}_{Y_{\left(\lambda_{\text {iso }}\right)}} / \mathrm{A}_{Y_{(\lambda \text { iso })}}\right]$ and has the same value of the absorptivity inverse at $\lambda_{\text {iso }}$ verified as follows:

$$
\begin{gathered}
(\mathrm{RCV})=\frac{P_{Y_{(\text {(iso) }}},}{A_{Y_{(\text {(iso })}}} \\
P_{Y_{(\text {(iso) }}}=\frac{a_{Y} C_{Y}}{a_{Y} C_{Y}}, \\
P_{Y_{(\text {(iso) }}}=\frac{C_{Y}}{C_{Y}}, \\
P_{Y_{(\text {(isso }}}=C_{Y}, \\
A_{Y_{(\text {iiso })}}=a_{\lambda \text { iso }} C_{Y} .
\end{gathered}
$$

$$
\begin{aligned}
(\mathrm{RCV}) & =\frac{P_{Y_{(\mathrm{iso})}}}{A_{Y_{(\mathrm{iso})}}} \\
& =\frac{C_{Y}}{a_{\lambda_{\mathrm{iso}}} C_{Y}} \\
& =\frac{1}{a_{\lambda \mathrm{iso}}} .
\end{aligned}
$$

However, $C Y$ is equal to $1 \mu \mathrm{g} / \mathrm{mL}$; therefore,

Dividing (3) by (4) to gain RCV at $\lambda_{\text {iso gives the }}$ following:

2.1.1. Absorptivity Factor. The $D^{0}$ absorption spectra of $X$ interfere with the $D^{0}$ absorption spectra of $Y$ at $\lambda_{\text {iso }}$, and $Y$ has a continuing region where the component $X$ has negligible absorption at $\lambda_{2}$.

The absorptivity factor $\left[a_{\lambda \text { iso }} / a_{\lambda 2}\right]$ between $\lambda_{\text {iso }}$ and $\lambda_{2}$ wavelengths is obtained for various concentrations of $Y$, and later, the mean of them is calculated and represented by the absorptivity factor.

2.1.2. Factorized Spectrum $\left(F S^{\prime}\right)$. Lotfy and Omran [29] recently defined the factorized spectrum of $Y$ as "a special spectrum that has absorbance value equal to one at $\lambda_{\text {iso }}$ which is acquired by dividing the $D^{0}$ spectra of $Y$ by its correlated absorbance value estimated at $\lambda_{\text {iso. }}$. Also, the factorized spectrum is applied for the analysis of other mixtures [30, 31]:

$$
\begin{aligned}
& \left(\mathrm{FS}^{\prime}\right)=\frac{A_{Y}}{A_{Y_{(\lambda \mathrm{iso})}}}, \\
& \left(\mathrm{FS}^{\prime}\right)=\frac{a_{Y} C_{Y}}{a_{Y_{(\lambda \mathrm{iso})}} C_{Y}}, \\
& \left(\mathrm{FS}^{\prime}\right)=\frac{a_{Y}}{a_{Y_{(\lambda \mathrm{iso})}} .}
\end{aligned}
$$

Spectra of the $X$ and $Y$ in their linearity range were scanned, and two calibration graphs were constructed between the absorbance of $D^{0}$ spectra and their corresponding concentrations.

Depending on absorptivity inverse value theory and after calculating both the constant and regression parameters, the a-centering method can be applied to recover the $D^{0}$ spectra of each $X$ and $Y$ in the binary mixture by applying three procedures: first, absorbance calculation at the isoabsorptive point ( $A_{\lambda \text { iso }}$ calculation), followed by recovering the spectrum, and finally, utilizing spectrum subtraction technique.

(1) Procedure $1 A_{\lambda i s o}$ calculation. For the more extended spectrum of $Y$ in the binary mixture $(X+Y)$, the absorptivity factor of $Y$ was used in order to gain the absorbance of $Y$ in the mixture at $\lambda_{\text {iso }}$ according to the following equation: 


$$
\begin{aligned}
& \frac{A_{Y(\lambda \text { iso })}}{A_{\lambda 2}}=\frac{a_{(\lambda \text { iso })} C_{Y}}{a_{\lambda 2} C_{Y}}, \\
& \frac{A_{Y(\lambda \text { iso })}}{A_{\lambda 2}}=\frac{a_{(\lambda \text { iso })}}{a_{\lambda 2}}, \\
& \frac{A_{Y(\lambda \text { iso })}}{A_{\lambda 2(\text { mix })}}=\frac{a_{(\lambda \text { iso })}}{a_{\lambda 2}}, \\
& A Y_{(\lambda \text { iso })}=\left[\frac{a_{(\lambda \text { iso })}}{a_{\lambda 2}}\right] * A_{\lambda 2 \text { (mix })},
\end{aligned}
$$

where $A Y_{(\lambda \text { iso })}$ represents the absorbance of $Y$ in the mixture at $\lambda_{\text {iso; }} ;\left[a_{(\lambda \text { iso })} / a_{\lambda 2}\right]$ represents the absorptivity factor; and $A_{\lambda 2 \text { (mix) }}$ represents the absorbance of the mixture at $\lambda 2$.

(2) Procedure 2 Recovering the spectrum. The $D^{0}$ spectrum of ( $Y$ ) can be recovered from the binary mixture $(X+Y)$ by using the normalized or factorized spectrum according to the analyzer's choice. If the analyzer chooses using normalized spectrum, the absorptivity inverse will be multiplied first by the obtained $A Y_{\left(\lambda_{\text {iso }}\right)}$ of $Y$ and, second, by the normalized spectrum $(Y)$.

However, if the analyzer chooses using the factorized spectrum, the obtained $A Y_{\left(\lambda_{\text {iso }}\right)}$ will be multiplied by the factorized spectrum.

(3) Procedure 3 Utilizing spectrum subtraction technique. The spectrum subtraction technique $[43,44]$ was used to recover the $D^{0}$ spectrum of $X$.

2.2. Ratio Subtraction (RS) Method. This method is considered as the original method for fingerprint resolution technique through which the $D^{0}$ spectra for the less continuous component $X$ in the binary mixture $(X+Y)$ can be obtained, through the following steps.

First, the mixture $(X+Y)$ is divided by a certain divisor $Y$ (optimization study will be applied to choose the best divisor) to gain a new curve representing $x / Y$ + constant.

Second, the constant is deleted by subtraction $x /$ Ý + constant - constant.

Third, the $D^{0}$ spectrum $(X)$ is acquired by multiplying $Y$ with the previous curve $(x / Y) * Y=X$.

2.3. Extended Ratio Subtraction (EXRS) Method. This method is considered as extension of the (RS) method through which (EXRS) can obtain the $D^{0}$ spectrum of $Y$, the more continuous spectrum in the binary mixture $(X+Y)$.

First, the previously obtained $D^{0}$ of $X$ within the (RS) method is divided by the certain divisor $\left(X^{\prime}\right)$ (optimization study will be applied to choose the best divisor) to get the constant $X / X^{\prime}$.

Second, the mixture $(X+Y)$ is divided by the same divisor $\left(X^{\prime}\right)$ to gain a new curve representing $\left(Y / X^{\prime}\right)+$ constant.

Third, the constant is deleted by subtraction $Y / X^{\prime}+$ constant - constant.
Fourth, the $D^{0}$ spectrum $(Y)$ is acquired by multiplying $X^{\prime}$ with the previous curve $\left(Y / X^{\prime}\right) * X^{\prime}=Y$.

2.4. Constant Multiplication (CM) Method. This method relates to the (RS) method; it depends on manipulating the obtained constant by applying the (RS) method. This constant $Y / Y$ is multiplied by $Y$ to obtain the $D^{0}$ spectrum of $Y$.

2.5. Unified Constant Subtraction (UCS) Method. In 2018, Lotfy and Saleh introduced UCS as a complementary method for the (RS) method through which the $D^{0}$ spectrum of $Y$ can be obtained after applying the (RS) method using the following steps.

First, the obtained spectrum of $X$ is divided by itself to gain constant value one: $(X / X)=1$.

Second, the mixture $(X+Y)$ is divided by $X$ to get a new curve: $(X+Y) / X=1+(Y / X)$.

Third, the value of one from the previous curve is deleted, and then, it is multiplied with $X$. As a result, the $D^{0}$ spectrum of $Y$ is obtained.

2.6. Spectrum Subtraction (SS) Method. The $D^{0}$ spectrum of $Y$ can be gained after applying the (RS) method by subtracting the obtained $D^{0}$ spectra of $X$ from the spectra of the mixture.

\section{Experimental}

3.1. Apparatus and Software. Spectrophotometric measurements were carried out on JASCO V-650 double-beam spectrophotometer, using matched $1.00 \mathrm{~cm}$ quartz cells. Scans were carried out in the range from 200.0 to $400.0 \mathrm{~nm}$. Spectra were automatically obtained by the JASCO software.

3.2. Materials and Reagents. Ciprofloxacin hydrochloride (CIP) was obtained from Unipharma Pharmaceutical Company, Damascus, Syria, and its purity percentage was observed to be $99.95 \pm 0.40$ according to the BP criteria [6]. Fluocinolone acetonide (FLU) was obtained from Medico Pharmaceutical Company, Homs, Syria, and its purity percentage was observed to be $99.97 \pm 0.77$ according to the BP criteria [6].

Otovel ${ }^{\circledR}$ otic vials, each vial comprising $0.25 \mathrm{~mL}$ solution of ciprofloxacin hydrochloride, amount to $0.75 \mathrm{mg}$ ciprofloxacin and $0.0625 \mathrm{mg}$ fluocinolone acetonide, and they are germ-free, additive-free, pure otic solutions.

Otovel ${ }^{\circledR}$ otic vials were factory-made by Arbor Pharmaceuticals under license of Laboratorios SALVAT in Barcelona (Spain).

Methanol of analytical grade was purchased from Panreac, Barcelona, Spain.

3.3. Solution Preparation. Standard stock solutions containing $1000.0 \mu \mathrm{g} / \mathrm{mL}$ of (CIP) and (FLU) were made separately in methanol. 
(CIP) and (FLU) working solutions (each, $50.0 \mu \mathrm{g} / \mathrm{mL}$ ) were prepared by diluting the previous stock solutions with methanol.

3.4. Spectral Characteristics. For studying the spectral characteristic of (CIP), (FLU), and the binary mixture of $(\mathrm{CIP})+(\mathrm{FLU})$, the absorption spectra were scanned against methanol as blank over the range of $200,0-400,0 \mathrm{~nm}$ for the $10.0 \mu \mathrm{g} / \mathrm{mL}$ of (CIP), $10.0 \mu \mathrm{g} / \mathrm{mL}$ of (FLU), and laboratory mixture (CIP + FLU) comprising $5.0 \mu \mathrm{g} / \mathrm{mL}$ of each in methanol.

\section{Procedure}

4.1. Linearity and Construction of Calibration Curves. The $D^{0}$ absorption spectra were recorded for the standard solutions of both (CIP) and (FLU) equivalent to 3.0-15.0 $\mu \mathrm{g} /$ $\mathrm{mL}$, respectively, prepared separately in the solvent mixture. Calibration curves were constructed for both (CIP) and (FLU) by plotting the absorbance of $D_{\max }^{0}$ (CIP at $278.0 \mathrm{~nm}$ and (FLU) at $238.0 \mathrm{~nm}$ ) against the concentrations in $\mu \mathrm{g} / \mathrm{mL}$ of (CIP) and (FLU), separately computed and used for all methods.

Laboratory-prepared working solutions of (FLU) in concentration $<3.0 \mu \mathrm{g} / \mathrm{mL}$ need to use the spectrum addition as the sample enrichment technique as follows: spectrum of pure (FLU) $(4.0 \mu \mathrm{g} / \mathrm{mL})$ was added to that of those mixtures in order to achieve the linearity of (FLU), to avoid the deviation of Beer's law which occurs in the case of low absorptivity for the minor component presented in the mixtures.

4.1.1. a-Centering Method of Both (CIP) and (FLU). Some spectral calculations were computed as follows:

(i) Absorptivity factor of pure (CIP) $\left(A_{248.2 \mathrm{~nm}} /\right.$ $\left.A_{318.2 \mathrm{~nm}}\right)$ for different concentrations of (CIP) was calculated at $318.2 \mathrm{~nm}$; the absorbance value for (FLU) at $318.2 \mathrm{~nm}$ is zero.

(ii) The stored absorption spectra of (CIP) were divided by $\mathrm{NS}_{\mathrm{CIP}}^{\prime}$, the normalized spectrum, to obtain ratio spectra of (CIP); then, the amplitudes at $248.2 \mathrm{~nm}$ $\left(\lambda_{\text {iso }}\right)\left(P_{\mathrm{CIP}(248.2 \mathrm{~nm})}\right)$ were recorded.

(iii) The response correlation value (RCV) was calculated for different concentrations of pure (CIP) as follows:

$$
\mathrm{RCV}=\frac{P_{\mathrm{CIP}(248.2 \mathrm{~nm})}}{A_{\mathrm{CIP}(248.2 \mathrm{~nm})}}
$$

(iv) Factorized spectrum of $\mathrm{FS}_{\mathrm{CIP}}^{\prime}$ is acquired by dividing the absorption spectrum of (CIP) by its absorbance value estimated at $248.2 \mathrm{~nm}$.

4.1.2. (RS) Method of (FLU). Special optimization study for choosing the best divisor of (CIP)' was done. Spectra of pure (FLU) were divided by the best spectrum divisor of (CIP)', and the constant obtained from the plateau region is subtracted. The $D^{0}$ spectrum of (FLU) is acquired by multiplying $(\mathrm{CIP})^{\prime}$ with the previous curve.
4.1.3. (EXRS) Method of (CIP). Special optimization study for choosing the best divisor of $(\mathrm{FLU})^{\prime}$ was done. Spectra of pure (CIP) were divided by the best spectrum divisor of (FLU) ${ }^{\prime}$, and the constant obtained from the plateau region is subtracted. The $D^{0}$ spectrum of (CIP) is acquired by multiplying FLU' with the previous curve.

4.1.4. CS Method of (CIP). Spectra of pure (CIP) were divided by the best spectrum divisor of $(\mathrm{CIP})^{\prime}$, the constant was obtained $\left(\mathrm{CIP} / \mathrm{CIP}^{\prime}\right)$ and multiplied by the divisor of $\left(\mathrm{CIP}^{\prime}\right)$, and the $D^{0}$ spectrum of $(\mathrm{CIP})$ is acquired.

4.1.5. UCS and SS Methods of (CIP). The calibration curve is constructed relating the absorbance of zero-order spectra of (CIP) at $278.0 \mathrm{~nm}$, and the corresponding concentrations and regression equations are computed.

4.2. Application to Laboratory-Prepared Mixtures. Different aliquots equivalent to $3.0-15.0 \mu \mathrm{g} / \mathrm{mL}$ for both (CIP) and (FLU) were separately prepared as two separate series of $10 \mathrm{~mL}$ volumetric flasks via appropriate dilution of their respective working solutions $(50.0 \mu \mathrm{g} / \mathrm{mL}$ of both (CIP) and (FLU)) using methanol. The prepared solutions were scanned in the range of $200.0-400.0 \mathrm{~nm}$ against methanol as a blank and stored in the computer.

For mixtures containing (FLU) in concentration less than $3.0 \mu \mathrm{g} / \mathrm{mL}$, standard spectrum addition is used via added spectrum of $4.0 \mu \mathrm{g} / \mathrm{mL}$ of pure standard (FLU) to every recorded spectrum of those mixtures by using JASCO software.

By measuring the difference between the total and added concentrations of (FLU), the claimed concentration of (FLU) in every mixture was acquired.

Mixtures containing (FLU) in concentration equals or more than $3.0 \mu \mathrm{g} / \mathrm{mL}$ are not required for spectrum adding technique.

The procedure previously mentioned for every technique was followed to obtain the concentrations of (CIP) and (FLU) within the laboratory-prepared mixtures.

4.3. Application to Pharmaceutical Formulation. The contents of one vial are dripped precisely into $100 \mathrm{~mL}$ volumetric flasks and then completed to the mark with methanol, and a solution with final concentration claiming $75.0 \mu \mathrm{g} / \mathrm{mL}$ of (CIP) and $6.25 \mu \mathrm{g} / \mathrm{mL}$ of (FLU) was obtained. The previous solution was filtered through a Whatman filter paper, and the volume was completed to $100 \mathrm{~mL}$ with methanol. To obtain a solution with final concentration claiming $12.0 \mu \mathrm{g} / \mathrm{mL}$ of (CIP) and $1.0 \mu \mathrm{g} / \mathrm{mL}$ of (FLU), a proper dilution was done.

The final concentration of (FLU) is $1.0 \mu \mathrm{g} / \mathrm{mL}$, so the recorded spectrum of pure (FLU) $(4.00 \mu \mathrm{g} / \mathrm{mL})$ was summed to those of the working solutions to achieve the linearity range of (FLU). The procedure described previously under each method was done to calculate the concentration of (CIP) and FLU in Otovel ${ }^{\circledR}$. 


\section{Results and Discussion}

Analytical methods for the determination of binary mixture without previous separation are of interest to quality control (QC) laboratories and national regulatory authorities (NRA) around the world.

The absorption spectra of (CIP) and (FLU) show partial overlap with the isoabsorptive point at $248.2 \mathrm{~nm}$ (Figure 2).

The application of the fingerprint resolution method for the determination of (CIP) and (FLU) in their binary mixture was investigated in this study within this method, and the $D^{0}$ spectra of the cited drugs were obtained by applying six spectrophotometric approaches regarding the synchronous evaluation of (CIP) and (FLU) in otic solution and in their pure form with a challengeable ratio of $12: 1$, respectively. Thus, (CIP) acts as the major component, while the (FLU) is the minor ones. The $D^{0}$ spectra of (CIP) and (FLU) presented intervention with partial overlap, and also, their spectra display isoabsorptive point, as shown in (Figure 3). Regrettably, (CIP), which is the main existing analyte within the Otovel ${ }^{\circledR}$ otic solution, is also of upper absorptivity, which complicates the (FLU) minor component estimation at its $\lambda_{\max }$, whereas (FLU) displays only slight absorbance specifically once appearing in minor concentrations. To solve this problem, spectrum addition technique was successfully applied.

Therefore, different spectral manipulating techniques have been applied for analysis of the cited drugs in their laboratory mixtures consisting of different proportions of the cited drugs and their combined otic formulation. The a-centering method was successfully applied to gain the concentration of both drugs, while the (RS) method could obtain the concentration of less extended ones (like FLU) only. Therefore, four complementary methods (EXRS), (CM, UCS, and SS) connected with the (RS) method to complete the resolution of this binary mixture. As a result, the concentration of (CIP) was obtained.

An optimization study was done to obtain the best divisor of (CIP) and (FLU) for (RS) and (EXRS) methods, respectively, as shown in Table 1 .

This study aimed mainly to develop procedures with satisfactory precision and accuracy for determining the binary mixture components presented in Otovel ${ }^{\circledR}$.

5.1. Absorptivity Centering (a-Centering) Method. Studying the spectral characteristic of (CIP), (FLU), and a binary mixture of them (CIP + FLU) has shown partially overlapping spectra and interference at a specific isoabsorptive point $\lambda_{\text {iso. In addition, (CIP) spectra are more continuous }}$ than (FLU) and showed wavelength at $318.2 \mathrm{~nm}$, which does not contribute with (FLU), as shown in Figure 3.

The a-Centering method can be applied to recover the zero-order spectra of both (CIP) and (FLU) in the binary mixture (CIP + FLU) by applying three procedures: first, $A_{\lambda \text { iso }}$ calculation is done, followed by recovering the spectrum of (CIP), and finally, utilizing the spectrum subtraction technique for recovering $D^{0}$ spectra of (FLU).

Before applying this method, some spectral calculation and regression equations were acquired as follows:

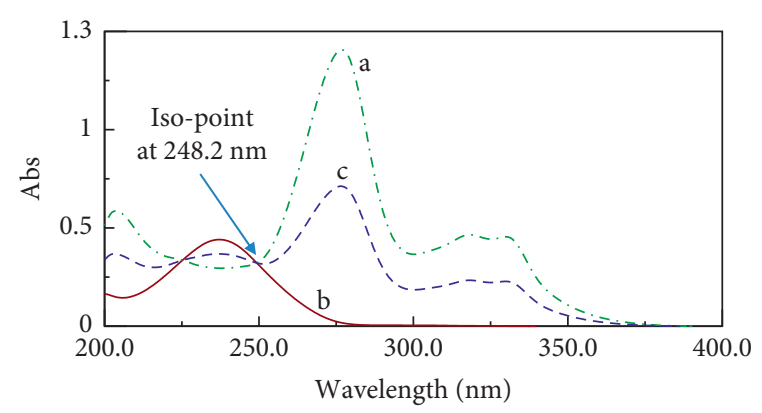

Figure 2: Zero-order spectra of (a) (CIP) $(10.0 \mu \mathrm{g} / \mathrm{mL})$, (b) FLU $(10.0 \mu \mathrm{g} / \mathrm{mL})$, and (c) a mixture containing $5.0 \mu \mathrm{g} / \mathrm{ml}$ of (CIP) and FLU showing the isoabsorptive point.

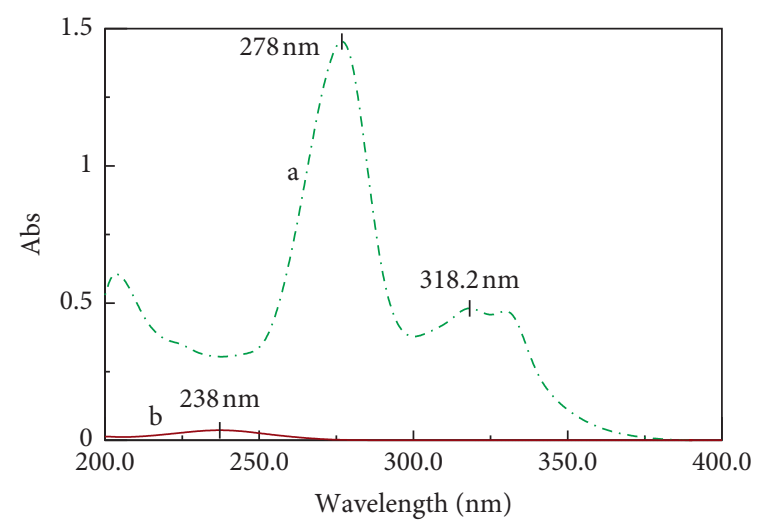

Figure 3: Zero-order spectra of (a) (CIP) $(12.0 \mu \mathrm{g} / \mathrm{mL})$ and (b) FLU $(1.0 \mu \mathrm{g} / \mathrm{mL})$ showing the ratio of the dosage form.

TABLE 1: Selection of the best divisor of (CIP) and FLU by the optimization study.

\begin{tabular}{|c|c|c|c|c|c|c|}
\hline \multirow{3}{*}{ Mix no. } & \multicolumn{6}{|c|}{ (CIP) divisors } \\
\hline & \multicolumn{2}{|c|}{$4.0 \mu \mathrm{g} / \mathrm{mL}$} & \multicolumn{2}{|c|}{$8.0 \mu \mathrm{g} / \mathrm{mL}$} & \multicolumn{2}{|c|}{$12.0 \mu \mathrm{g} / \mathrm{mL}$} \\
\hline & Post* & $\operatorname{Rec}^{* *}$ & Post* & $\operatorname{Rec}^{* *}$ & Post $^{*}$ & $\operatorname{Rec}^{* *}$ \\
\hline 1 & 1.250 & 1.277 & 0.625 & 0.632 & 0.417 & 0.422 \\
\hline 2 & 2.500 & 2.5 & 1.250 & 59 & 3 & 0.842 \\
\hline 3 & 1.000 & 1.020 & 0.500 & .537 & 0.333 & 0.326 \\
\hline 4 & 1.000 & 1.028 & 0.500 & 0.503 & 0.333 & 0.331 \\
\hline 5 & 000 & 2.0 & 1.000 & 0.980 & 0.667 & 0.645 \\
\hline \multirow[t]{2}{*}{$\mathrm{AAD}^{* * *}$} & \multicolumn{2}{|c|}{0.033} & \multicolumn{2}{|c|}{0.015} & \multicolumn{2}{|c|}{0.009} \\
\hline & \multirow{2}{*}{\multicolumn{2}{|c|}{$4.0 \mu \mathrm{g} / \mathrm{mL}$}} & \multicolumn{2}{|c|}{ FLU divisors } & \multirow{2}{*}{\multicolumn{2}{|c|}{$12.0 \mu \mathrm{g} / \mathrm{mL}$}} \\
\hline \multirow[t]{2}{*}{ Mix no. } & & & 8.0 & $/ \mathrm{mL}$ & & \\
\hline & Post* & $\operatorname{Rec}^{* *}$ & Post* & $\operatorname{Rec}^{* *}$ & Post $^{*}$ & $\operatorname{Rec}^{* *}$ \\
\hline 1 & 1.250 & 1. & 0.625 & $0 . t r-x$ & 0.417 & 0.421 \\
\hline 2 & 1.000 & 1.041 & 0.500 & 0.488 & 0.333 & 0.343 \\
\hline 3 & 2.500 & 2.452 & 1.250 & 1.271 & 0.833 & 0.845 \\
\hline 4 & 2.000 & 2.013 & 1.000 & 1.002 & 0.667 & 0.668 \\
\hline 5 & 1.000 & 1.018 & 0.500 & 0.482 & 0.333 & 0.331 \\
\hline $\mathrm{AAD}^{* * *}$ & \multicolumn{2}{|c|}{0.044} & \multicolumn{2}{|c|}{0.013} & \multicolumn{2}{|c|}{0.006} \\
\hline
\end{tabular}

The values represent the constant at the plateau regions $(300.0-330.0 \mathrm{~nm})$ for (CIP) and (220.0-260.0 nm) for FLU. *Post: postulated value of constant; ${ }^{* *}$ Rec: recorded value of constant; ${ }^{* * *} \mathrm{AAD}$ : average absolute difference between postulated and recorded constant values.

(i) Calculating absorptivity inverse value $\left(1 / a_{\lambda \text { iso }}\right)$ by using Excel software: absorbance at $248.2 \mathrm{~nm}\left(\lambda_{\text {iso }}\right)$ was measured using the $D^{0}$ spectra of (CIP) ranged between $3.0-15.0 \mu \mathrm{g} / \mathrm{mL}$ to get its corresponding 
absorptivity; it was found from equation (1) that $a_{\mathrm{CIP}(248.2 \mathrm{~nm})}$ equals 0.027 , and as a result, absorptivity inverse $\left(1 / a_{\mathrm{CIP}(248.2 \mathrm{~nm})}\right)$ was 36.98 . Getting absorptivity inverse value $\left(1 / a \lambda_{\text {iso }}\right)$ by using spectrophotometric software: the scanned $D^{0}$ spectra of (CIP) $(1.0-15.0 \mu \mathrm{g} / \mathrm{mL})$ were divided by the normalized spectrum of (CIP)', and amplitudes of the obtained ratio spectra of (CIP) at $\lambda_{\text {iso }}\left(P_{\operatorname{CIP}(248.2 \mathrm{~nm})}\right)$ were registered. Using equation (5), RCV between $P_{\mathrm{CIP}(248.2 \mathrm{~nm})}$ of various concentrations of (CIP) versus its corresponding $A_{\mathrm{CIP}(248.2 \mathrm{~nm})}$ registered the value 36.98 and represented the same value of absorptivity inverse $\left(1 / a \lambda_{\text {iso }}\right)$.

(ii) Absorptivity factor $\left(a_{248.2 \mathrm{~nm}} / a_{318.2 \mathrm{~nm}}\right)$ was calculated and registered 0.68 .

(iii) The normalized and factorized spectrum of (CIP) were obtained.

(iv) (FLU) determination by the spectrum addition technique: the $D^{0}$ spectrum $4.0 \mu \mathrm{g} / \mathrm{mL}$ of pure standard (FLU) using UV spectrum software was added to those of all laboratory-prepared mixtures containing (FLU) in concentration less than $3.0 \mu \mathrm{g} /$ $\mathrm{mL}$ and in pharmaceutical preparation. By measuring the difference between the total and added concentrations of (FLU) in each mixture, the real concentration of (FLU) was acquired.

(v) Spectra of the (CIP) and (FLU) in their linearity range were scanned, and two calibration graphs were built up between the $D^{0}$ spectrum of (CIP) at $278.0 \mathrm{~nm}$ and that of (FLU) at $238.0 \mathrm{~nm}$ against their corresponding concentrations.

After calculating this constant parameter values and regression parameters, we can apply the a-centering method in three steps:

Step 1. Obsorbance calculation at the isoabsorptive point $[A 248.2 \mathrm{~nm}]$. Laboratory mixtures were measured at $318.2 \mathrm{~nm}$, then absorbance of (CIP) at $\lambda_{\text {iso }} 248.2 \mathrm{~nm}$ was gained in these mixtures through the following equation:

$$
A_{248.2 \mathrm{~nm}}=\left(\frac{a_{248.2 \mathrm{~nm}}}{a_{318.2 \mathrm{~nm}}}\right) \times A_{318.2 \mathrm{~nm}(\mathrm{mix})},
$$

where $A_{248.2 \mathrm{~nm}}$ represents the absorbance of (CIP) in the mixture at $\lambda_{\text {iso }} 248.2 \mathrm{~nm}$ and $\left(a_{248.2 \mathrm{~nm}} / a_{318.2 \mathrm{~nm}}\right)$ represents the absorptivity factor, which is equal to 0.681 .

Step 2. Spectrum recovery. In order to recover the $D^{0}$ spectrum of (CIP) in every mixture, multiply the gained $A_{248.2 n m}$ of (CIP) in every laboratory mixture by absorptivity inverse $\left[1 / a_{\mathrm{CIP}(248.2 \mathrm{~nm})}\right]$ calculated at $\lambda_{\text {iso }} 248.2 \mathrm{~nm}$, which was found to be 36.98 , and then the result is multiplied by the (CIP)' normalized spectrum, as shown in Figure 4.

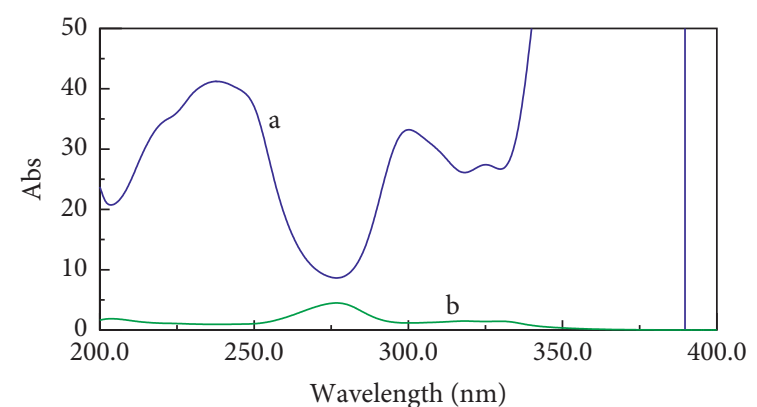

Figure 4: $5.0 \mu \mathrm{g} / \mathrm{ml}$ of (CIP) spectra representing. (a) Absorptivity inverse (1/a) of (CIP), and (b) Factorized spectrum of (CIP) (FS').

$$
\begin{aligned}
& D_{\text {recovered (CIP) }}^{0}=A_{248.2 \mathrm{~nm}(\lambda \text { iso })} \times\left[\frac{1}{a_{\mathrm{CIP}(248.2 \mathrm{~nm})}}\right], \\
& D_{\text {recovered(CIP) }}^{0}=A_{248.2 \mathrm{~nm}\left(\lambda_{\text {iso })}\right.} \times 36.98,
\end{aligned}
$$

or by directly multiplying the obtained $A_{248.2 \mathrm{~nm} \text { ( }(\text { iso) }}$ by the $\mathrm{FS}_{\mathrm{CIP}}^{\prime}$ factorized spectrum of (CIP) to get the $D^{0}$ absorption spectrum of (CIP) in each mixture, as shown in Figure 4:

$$
D_{\text {recovered(CIP) }}^{0}=A_{248.2 \mathrm{~nm}\left(\lambda_{\text {iso })}\right.} \times \mathrm{FS}_{\mathrm{CIP}}^{\prime} .
$$

Step 3. Spectrum subtraction. To gain the $D^{0}$ spectrum of (FLU) in the mixture, subtract the gained $D^{0}$ spectrum of (CIP) from the $D^{0}$ absorption spectrum of the corresponding mixture.

From the above, (CIP) and (FLU) concentrations were estimated using their regression equations at their $\lambda_{\max }$.

The absorptivity centering method (a-Centering) via the normalized spectrum involves several manipulating steps, so it is more convenient when applied via the factorized spectrum.

This approach has an improvement that it is able to determine the concentrations of both mentioned drugs by their unified regression equation, and the use of normalized and factorized spectra minimizes the mistake in measurement of concentrations of the minor component (FLU) in binary mixtures.

5.2. Ratio Subtraction (RS) Method. In the ratio subtraction method, the important step is to choose the best concentration's divisor. First, an optimization study was done by taking three concentrations of (CIP) within their linearity (4.0, 8.0, and $12.0 \mu \mathrm{g} / \mathrm{mL}$ ), then the laboratory-prepared mixtures were divided separately by these three concentrations, the constant $\left(\mathrm{CIP} / \mathrm{CIP}^{\prime}\right)$ was measured in the plateau region $(300.0-330.0 \mathrm{~nm})$, and the results obtained were compared to the theoretical results and judged according to the minimum average absolute difference between theoretical and acquired constants. The 
concentration $12.0 \mu \mathrm{g} / \mathrm{mL}$ of (CIP) gave the best result, as shown in Table 1.

(FLU) only was estimated by this technique through dividing the spectra of the laboratory-prepared mixtures $(\mathrm{CIP}+\mathrm{FLU})$ by $12.0 \mu \mathrm{g} / \mathrm{mL}\left(\mathrm{CIP}^{\prime}\right)$ divisor in order to gain a new curve representing $\left(\mathrm{CIP} / \mathrm{CIP}^{\prime}\right)+\left(\mathrm{FLU} / \mathrm{CIP}^{\prime}\right)=$ $\left({\text { FLU } / \mathrm{CIP}^{\prime}}^{\prime}\right)+$ constant.

The constant mentioned above was determined in the plateau region $(300.0-330.0 \mathrm{~nm})$ and subtracted from the previous equation, as shown in Figure 5. Finally, by multiplying FLU/CIP ${ }^{\prime}$ with divisor $12.0 \mu \mathrm{g} / \mathrm{mL}\left(\mathrm{CIP}^{\prime}\right)$, the $D^{0}$ spectra of (FLU) will be obtained from the binary mixture $(\mathrm{CIP}+\mathrm{FLU})$.

For the (FLU) determination in the laboratory-prepared mixtures containing (FLU) in concentration less than $3.0 \mu \mathrm{g} /$ $\mathrm{mL}$ and in pharmaceutical preparations, the spectrum addition technique was applied as mentioned above in a-centering method.

The (RS) method is applied through four manipulating steps for determining the less extended component (FLU) at its $\lambda_{\max }$, and thus supplementary methods are required to complete the determination of the other component (CIP) of the binary mixture. In addition, selecting the best divisor and plateau region and using the pure form of the more extended component as a divisor are required in order to complete the analysis; however, the (RS) method can applied without need for special software or derivative steps.

In order to complete the resolution process after applying the (RS) method and acquire the $D^{0}$ spectra of (FLU) from the binary mixtures (CIP) and FLU, one of the following methods was combined with the (RS) method and successfully applied for the determination of (CIP) and to extract its zero-order absorption spectrum, thereby getting its concentrations using regression equation at its maxima:

5.2.1. Extended Ratio Subtraction (EXRS) Method. The $\mathrm{D}^{0}$ spectra of (FLU) obtained by the (RS) method was divided by a divisor $\left(\mathrm{FLU}^{\prime}\right) 12.0 \mu \mathrm{g} / \mathrm{mL}$, which was found to be the best divisor obtained by optimization of three concentrations of (FLU) (4.0, 8.0, and $12.0 \mu \mathrm{g} / \mathrm{mL})$ within their linearity.

The constant value of FLU/FLU' was estimated at the 220.0-260.0 nm plateau region.

The spectra of laboratory-prepared mixtures were divided by a divisor $\left(\mathrm{FLU}^{\prime}\right) 12.0 \mu \mathrm{g} / \mathrm{mL}$, and the ratio spectra were gained, the constant FLU' was subtracted from the previous ratio spectra, and later those ratio spectra were multiplied by FLU' in order to obtain $D^{0}$ of (CIP), as shown in Figure 6.

The (EXRS) method consists of four manipulating steps: choose the best divisor, get the ratio spectra, subtract the constant, and multiply by the divisor.

These several steps make the (EXRS) method more timeconsuming while applying for binary mixture analysis.

The advantages of using the (EXRS) method in analysis of the binary mixture are that no special software is required for applying this technique, accurate results are obtained through it, and also it recovers the pure $D^{0}$ spectra of the (CIP) component with no interference.

The disadvantages of this method are that accurate measurement of a constant is required and using the pure form of the divisor and choosing the best concentration of the divisor.

5.2.2. Constant Multiplication (CM) Method. The constant CIP/CIP' obtained by the (RS) method was multiplied by (CIP)' to gain the $D^{0}$ spectra of (CIP).

This complementary method $(\mathrm{CM})$ does not require using a divisor to complete the analysis of binary mixture, and also just two steps are required to complete the determination of (CIP), which make it a simple method when applied. But, the only limitation is that the calculation of (CIP) is dependent on the recorded constant $\mathrm{CIP} / \mathrm{CIP}^{\prime}$, so the risk of error results is increased.

5.2.3. Unified Constant Subtraction (UCS) Method. The spectra of laboratory-prepared mixtures (CIP + FLU) was divided by an (FLU)' divisor, obtained from the (RS) method, in order to obtain a new curve representing $\left(\mathrm{CIP} / \mathrm{FLU}^{\prime}\right)+\left(\right.$ FLU/FLU $\left.{ }^{\prime}\right)=\left(\mathrm{CIP} / \mathrm{FLU}^{\prime}\right)+$ constant. The constant value is one in this equation; if the value one is subtracted from the previous equation and then multiplied by $(\mathrm{FLU})^{\prime}$, the $D^{0}$ spectra of (CIP) are obtained. This complementary method (UCS) does not require an optimization study to choose the best divisor to obtain the $D^{0}$ of (CIP), and also it does not require any pure form of (CIP) to complete the determination of the binary mixture components, but the only limitation of this method is more time consumption since it consists of three steps.

5.2.4. Spectrum Subtraction (SS) Method. The spectra of (CIP) in zero-order form were obtained from the binary mixture (CIP + FLU) by subtracting the spectra of (FLU), which was obtained by the (RS) method from the spectra of the binary mixture. This approach has advantage of being simple and having a few steps to get the $D^{0}$ spectra of (CIP) without requirement of a special divisor or a recorded constant, but the limitation of this method is the noise interfering when acquired (CIP) by subtraction.

Calibration equations and concentration ranges for all the proposed methods are mentioned in Table 2. The proposed techniques were successfully effectively applied for (CIP) and (FLU) analysis in their laboratory-prepared mixtures containing different ratios of (CIP) and (FLU), as shown in Table 3 . The proposed procedures were also applied for the determination of Otovel ${ }^{\circledR}$ ear drops after applying spectrum adding techniques, as shown in Table 3.

\section{Method Validation}

The six proposed approaches were validated in compliance with the ICH guideline [40] with respect to methods' range, 




Figure 5: (a) Zero-order absorption spectrum of (CIP) ${ }^{\prime}(12.0 \mu \mathrm{g} / \mathrm{mL})$ as a divisor; (b) zero-order absorption spectrum of a mixture of (CIP) and FLU $\left(5.0 \mu \mathrm{g} / \mathrm{ml}\right.$ each); (c) ratio spectrum of this mixture using of $(\mathrm{CIP})^{\prime}(12.0 \mu \mathrm{g} / \mathrm{mL})$ as a divisor showing in the plateau region $(300.0-330.0 \mathrm{~nm})$.

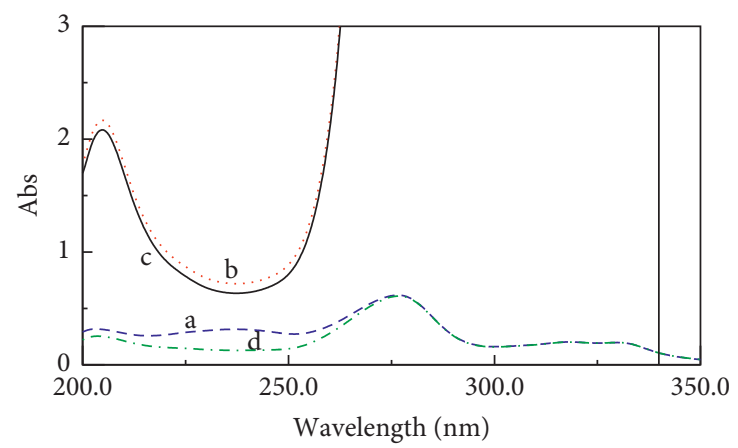

Figure 6: The spectra obtained by using the EXRS method. (a) A mixture containing $5.0 \mu \mathrm{g} / \mathrm{ml}$ of each (CIP) and FLU; (b) the mixture after divided by $12.0 \mu \mathrm{g} / \mathrm{mL}$ of $\mathrm{FLU}^{\prime}$; (c) the mixture after subtracting the constant; (d) the pure (CIP) obtained after multiplied by FLU'.

TABLE 2: Assay parameters and validation sheets for pure cited drugs at their maxima.

\begin{tabular}{lcc}
\hline Parameter & CIP $^{*}$ & FLU $^{* *}$ \\
\hline Wavelength $(\mathrm{nm})$ & 278.0 & 238.0 \\
$N$ & 7 & 7 \\
Range $(\mu \mathrm{g} / \mathrm{mL})$ & $3.0-15.0$ & $3.0-15.0$ \\
Intercept & -0.0007 & -0.0011 \\
Slope & 0.1209 & 0.0357 \\
Correlation coefficient & 0.9999 & 0.9999 \\
Accuracy $^{\mathrm{a}, \mathrm{b}}$ & $100.08 \pm 0.51$ & $99.79 \pm 0.54$ \\
Repeatability $^{\mathrm{a}, \mathrm{c}}$ & 0.43 & 0.82 \\
Interday precision $^{\mathrm{a}, \mathrm{c}}$ & 1.19 & 1.03 \\
\hline
\end{tabular}

${ }^{*}$ a-Centering, EXRS, CM, UCS, and SS. ${ }^{* *}$ a-Centering and RS. ${ }^{a}$ Average of three experiments. ${ }^{b}$ Mean \pm standard deviation. ${ }^{c} \mathrm{RSD} \%$ of concentrations (4.0, 8.0, and $12.0 \mu \mathrm{g} / \mathrm{mL}$ of both CIP and FLU).

linearity, accuracy, and precision, as shown in Table 2. The suggested methods (a-centering, (EXRS), CM, UCS, and SS) have the same results for determination of (FLU), and a-centering and (RS) methods have the same results for determination of (CIP), and this is because all methods regained the zero-order absorption spectra of the studied drugs. Thus, the concentration of each drug was calculated using calibration curves representing absorbance at its maxima versus its corresponding concentration. Table 3 shows the results obtained from the analysis of laboratory-prepared mixtures containing different ratios of (CIP) and (FLU), ensuring the selectivity of the proposed methods where satisfactory results were obtained over the calibration range. The proposed methods were also performed for the determination of the drugs in Otovel ${ }^{\circledR}$ otic solution, where satisfactory results were obtained, as shown in Table 3.

\section{Statistical Analysis}

Table 4 shows the calculated $t$ and $F$ values for the statistical comparison of the results obtained by the proposed methods and the official ones [6]. Table 5 shows one-way ANOVA statistical comparison of the results obtained by the proposed approaches and the official methods when applied to Otovel ${ }^{\circledR}$ otic solution. The results from both tables showed that there was no significant difference between the proposed approaches and the official ones with respect to accuracy and precision.

7.1. Comparative Study between the Developed and Reported Spectrophotometric Methods [28]. Table 6 illustrates the advantages and limitations of each of the developed fingerprint spectrophotometric methods, and it was clear that all the developed methods have several unified advantages that they are able to recover and determine the component of both at their $\lambda_{\max }$, so maximum accuracy, precision, and reproducibility without any need for purchasing special software. In addition, the recovered spectra were typical to that of pure components which confirm the spectral profile of each component of interest. These advantages besides the minimum limitation made them superior over the reported spectrophotometric methods [28]. 


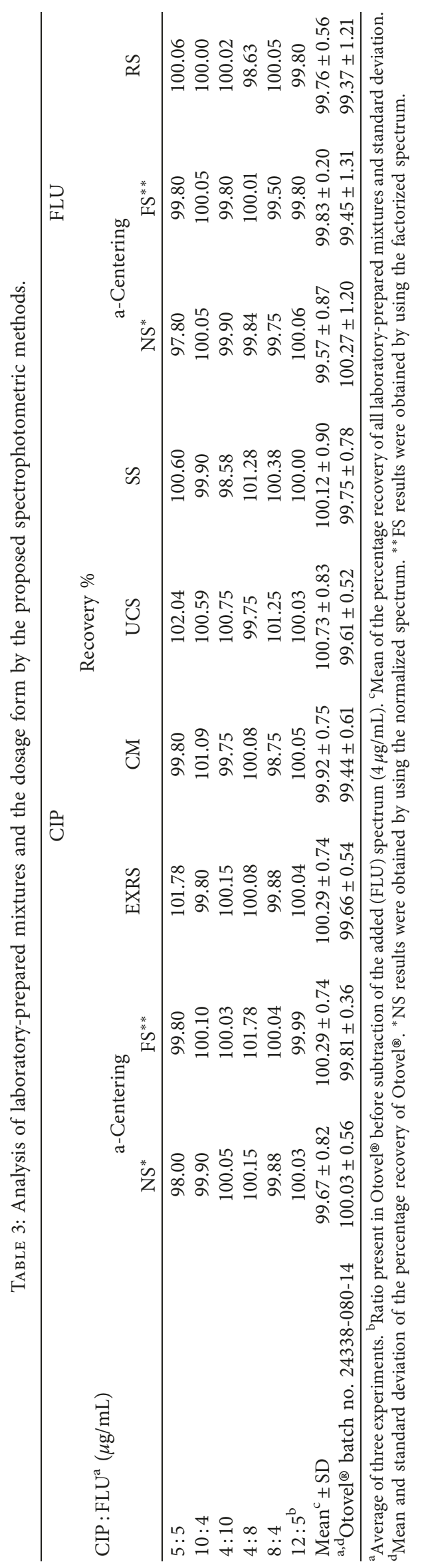


TABLE 4: Statistical comparison between the results obtained by the proposed spectrophotometric methods and official methods [6] for the determination of CIP and FLU in Otovel ${ }^{\circledR}$ otic solution.

\begin{tabular}{|c|c|c|c|c|c|c|c|c|c|c|c|}
\hline \multirow{3}{*}{ Methods } & \multicolumn{7}{|c|}{ CIP } & \multicolumn{4}{|c|}{ FLU } \\
\hline & \multicolumn{2}{|c|}{ a-Centering } & \multirow{2}{*}{ EXRS } & \multirow{2}{*}{$\mathrm{CM}$} & \multirow{2}{*}{ UCS } & \multirow{2}{*}{ SS } & \multirow{2}{*}{$\mathrm{BP}^{\mathrm{a}}$} & \multicolumn{2}{|c|}{ a-Centering } & \multirow{2}{*}{ RS } & \multirow{2}{*}{$\mathrm{BP}^{\mathrm{a}}$} \\
\hline & NS* & $\mathrm{FS}^{* *}$ & & & & & & NS* & $\mathrm{FS}^{* *}$ & & \\
\hline Mean & 100.03 & 99.81 & 99.66 & 99.44 & 99.61 & 99.89 & 99.85 & 100.27 & 99.45 & 99.37 & 99.73 \\
\hline SD & 0.56 & 0.36 & 0.54 & 0.61 & 0.52 & 0.64 & 0.32 & 1.20 & 1.31 & 1.21 & 0.61 \\
\hline Variance & 0.31 & 0.13 & 0.29 & 0.37 & 0.27 & 0.42 & 0.10 & 1.45 & 1.73 & 1.46 & 0.37 \\
\hline$N$ & 6 & 6 & 6 & 6 & 6 & 6 & 6 & 6 & 6 & 6 & 6 \\
\hline$t$-Test ${ }^{\mathrm{b}}$ & 0.86 & 0.18 & 0.73 & 1.46 & 0.96 & 0.14 & - & 0.97 & 0.48 & 0.66 & - \\
\hline$F$ value $^{c}$ & 3.01 & 1.27 & 2.80 & 3.55 & 2.63 & 4 & - & 3.87 & 4.61 & 3.90 & - \\
\hline
\end{tabular}

${ }^{a}$ The BP method for (CIP) is HPLC, while a the BP method for FLU is the absorption method. ${ }^{\mathrm{b}}$ The corresponding tabulated value of Student's $t$-test is equal to 2.23 at $p=0.05$. ${ }^{\circ}$ The corresponding tabulated value of $F$ is equal to 5.05 at $p=0.05 .{ }^{*} \mathrm{NS}$ results were obtained by using the normalized spectrum. ${ }^{* *} \mathrm{FS}$ results were obtained by using the factorized spectrum.

TABLE 5: Results of one-way ANOVA for comparison of the proposed and the official methods [6] for determination of (CIP) and FLU in Otovel ${ }^{\circledR}$ otic solution.

\begin{tabular}{|c|c|c|c|c|c|c|c|}
\hline \multicolumn{2}{|c|}{ Source of variation } & Degree of freedom & Sum of squares & Mean square & $p$ value $^{\mathrm{a}}$ & $F$ value $^{\mathrm{a}}$ & $F$ critical $^{\mathrm{a}}$ \\
\hline \multirow{3}{*}{ CIP } & Between columns & 6 & 1.41 & 0.24 & & & \\
\hline & Within columns & 35 & 9.49 & 0.27 & 0.53 & 0.87 & 2.37 \\
\hline & Total & 41 & 10.90 & & & & \\
\hline \multirow{3}{*}{ FLU } & Between columns & 3 & 2.97 & 0.99 & & & \\
\hline & Within columns & 20 & 25.07 & 1.25 & 0.51 & 0.79 & 3.10 \\
\hline & Total & 23 & 28.05 & & & & \\
\hline
\end{tabular}

aThere was no significance difference between the methods using one-way ANOVA at $p<0.05$.

TABLE 6: Advantages and limitations of each fingerprint method used for the analysis of co-formulated otic solution of ciprofloxacin and fluocinolone acetonide in their challengeable ratio.

\begin{tabular}{|c|c|c|}
\hline Method & Advantages & Limitations \\
\hline $\begin{array}{l}\text { a-Centering via normalized } \\
\text { spectrum }\end{array}$ & $\begin{array}{l}\text { (1) Measurement was done in zero order } \\
\text { (2) It is able to recover and determine the } \\
\text { component of both at their } \lambda_{\max } \text {, so it gives } \\
\text { maximum accuracy and reproducibility } \\
\text { (3) Obtaining spectra typical to that of pure } \\
\text { components which confirm the spectral profile of } \\
\text { each component of interest } \\
\text { (4) No need for special software } \\
\text { (5) Needs calculation of one factor } \\
\text { (6) Easy and accurate }\end{array}$ & $\begin{array}{l}\text { (1) Four manipulation steps } \\
\text { (2) Calculation of two factors } \\
\text { (3) Presence of isopoints } \\
\text { (4) Preparing the normalized spectrum via } \\
\text { spectrophotometer software }\end{array}$ \\
\hline
\end{tabular}

(1) Measurement was done in zero order

(2) It is able to recover and determine the component of both at their $\lambda_{\max }$, so it gives

maximum accuracy and reproducibility

(3) Obtaining spectra typical to that of pure

a-Centering via factorized spectrum components which confirm the spectral profile of each component of interest

(4) No need for special software

(5) Needs calculation of one factor

(6) Simple preparation of the factorized spectrum
(1) Three manipulation steps

(2) Presence of isopoints

(3) Preparing the factorized spectrum via spectrophotometer software
(7) Easy and accurate

(1) It is able to determine the nonextended component at its $\lambda_{\max }$ with maximum accuracy and reproducibility

Ratio Subtraction (RS)

(2) Obtaining spectra typical to that of pure components which confirm the spectral profile of each component of interest

(3) No need for special software
(1) Three manipulation steps

(2) Recovery of zero order for the less extended spectra only

(3) Availability of the pure drug of the component with extended spectrum as a divisor

(4) Optimization study for choosing the best concentration of the divisor 
TABLE 6: Continued.

\begin{tabular}{|c|c|c|}
\hline Method & Advantages & Limitations \\
\hline Extended Ratio Subtraction (EXRS) & $\begin{array}{l}\text { (1) It is able to determine the extended } \\
\text { component at its } \lambda_{\max } \text { with maximum accuracy } \\
\text { and reproducibility } \\
\text { (2) Obtaining spectra typical to that of pure } \\
\text { components which confirm the spectral profile of } \\
\text { each component of interest } \\
\text { (3) No need for special software }\end{array}$ & $\begin{array}{l}\text { (1) Four manipulation steps } \\
\text { (2) Recovered the } D_{0} \text { spectra of the more } \\
\text { extended one only } \\
\text { (3) Accurate measuring of a constant is required } \\
\text { (4) Need for the pure drug of the component with } \\
\text { the nonextended spectrum as a divisor } \\
\text { (5) Optimization study was applied to choose the } \\
\text { best concentration of the divisor }\end{array}$ \\
\hline
\end{tabular}

(1) Two manipulation steps

Constant Multiplication (CM)
(1) No need for special software (2) No need for isopoint

(3) No need for calculated factor
(2) Accurate measuring of a constant is required

(3) Need for the pure sample of the drug of interest as a divisor

(4) Optimization study was applied in order to choose the best concentration of the divisor

(1) Measurement was done on ratio spectra

(2) No need for isopoint

Unified Constant Subtraction (UCS)

(3) No need for pure form, divisors, or calculated factors

(1) Three manipulation steps

(2) Complementary method for the RS method

(1) No need for isopoint

Spectrum Subtraction (SS)

(2) No need for pure form, divisors, or calculated factors

(1) Applied only as a complementary method

(3) One-step manipulation

\section{Conclusion}

This report delivered the utility of new, uncomplicated, green, economic spectrophotometric approaches for the determination of the recently delivered binary combination of (CIP) and (FLU). The a-centering method have the optimum efficiency power to determine both analytes depending on the isosbestic point theory; however the (RS) method could determine only one analyte, but supplementary methods (EXRS), (CM, UCS, and SS) connected with (RS) solved this problem; therefore, the two analytes could be determined with accurate results. The supplementary methods differed in the number of handling steps where (EXRS) involves four handling steps, CM consists of two steps, UCS consists of three steps, and SS consists of only one step and both methods were applied using one divisor only. Furthermore, while operating with these techniques, which belong to the fingerprint resolution technique, all determinations were done after recovering the zero-order spectra for each component from their mixture that allow estimation of each component in their zero-order regression equation. As a final point, it is seen that the suggested fingerprint resolution technique is the only spectrophotometric method which could be used in resolving complex matrices and testing the purity of the resolved spectra. These proposed methods could be utilized within the routine analysis in QC research laboratory.

\section{Data Availability}

The data used to support the findings of this study are included within the article.

\section{Conflicts of Interest}

The authors declare that there are no conflicts of interest.

\section{References}

[1] M. Ghosh, "Clinical review," NDA 208251.505 (B) (2) 2016, https://www.fda.gov/downloads/Drugs/DevelopmentApproval Process/DevelopmetResources/UCM503854.pdf.

[2] E. Abelardo, L. Pope, K. Rajkumar, R. Greenwood, and D. A. Nunez, "A double-blind randomised clinical trial of the treatment of otitis externa using topical steroid alone versus topical steroid-antibiotic therapy," European Archives of OtoRhino-Laryngology, vol. 266, no. 1, pp. 41-45, 2009.

[3] R. Mösges, C. M. Domröse, and J. Löffler, "Topical treatment of acute otitis externa: clinical comparison of an antibiotics ointment alone or in combination with hydrocortisone acetate," European Archives of Oto-Rhino-Laryngology, vol. 264, no. 9, pp. 1087-1094, 2007.

[4] H. M. Lotfy, M. A. Hegazy, S. Mowaka, and E. H. Mohamed, "Novel spectrophotometric methods for simultaneous determination of amlodipine, valsartan and hydrochlorothiazide in their ternary mixture," Spectrochimica Acta Part A: Molecular and Biomolecular Spectroscopy, vol. 140, pp. 495-508, 2015.

[5] S. C. Sweetman, Martindale: 6e Complete Drug Reference, Pharmaceutical Press, London, UK, 2009.

[6] The Stationery Office on Behalf of the Medicines and Healthcare Products Regulatory Agency (MHRA), Vol. II, British Pharmacopoeia, London, UK, 2013.

[7] The United States Pharmacopeia, National Formulary38, NF 33, United States Pharmacopeial Convention INC, North Bethesda, MD, USA, 2015.

[8] A. M. El-Brashy, M. El-Sayed Metwally, and F. A. El-Sepai, "Spectrophotometric determination of some fluoroquinolone antibacterials by binary complex formation with xanthene dyes," Il Farmaco, vol. 59, no. 10, pp. 809-817, 2004.

[9] G. H. Ragab and A. S. Amin, "Spectrophotometric determination of certain cephalosporins in pure form and in pharmaceutical formulations," Spectrochimica Acta Part A: 
Molecular and Biomolecular Spectroscopy, vol. 60, no. 12, pp. 2831-2835, 2004.

[10] S. T. Ulu and S. Tatar, "Spectrofluorimetric determination of fluoroquinolones in pharmaceutical preparations," Spectrochimica Acta Part A: Molecular and Biomolecular Spectroscopy, vol. 72, no. 1, pp. 138-143, 2009.

[11] E. F. Elkady and M. A. Mahrouse, "Reversed-phase ion-pair HPLC and TLC-densitometric methods for the simultaneous determination of ciprofloxacin hydrochloride and metronidazole in tablets," Chromatographia, vol. 73, no. 3-4, pp. 297-305, 2011.

[12] Y.-L. Feng and C. Dong, "Simultaneous determination of trace ofloxacin, ciprofloxacin, and sparfloxacin by micelle TLC-fluorimetry," Journal of Chromatographic Science, vol. 42, no. 9, pp. 474-477, 2004.

[13] E. C. L. Cazedey, D. P. Perez, J. P. Perez, and H. R. N. Salgado, "LC assay for ciprofloxacin hydrochloride ophthalmic solution," Chromatographia, vol. 69, no. S2, pp. 241-244, 2009.

[14] R. Galarini, L. Fioroni, F. Angelucci, G. R. Tovo, and E. Cristofani, "Simultaneous determination of eleven quinolones in animal feed by liquid chromatography with fluorescence and ultraviolet absorbance detection," Journal of Chromatography A, vol. 1216, no. 46, pp. 8158-8164, 2009.

[15] A. F. Faria, M. V. N. de Souza, M. V. de Almeida, and M. A. L. de Oliveira, "Simultaneous separation of five fluoroquinolone antibiotics by capillary zone electrophoresis," Analytica Chimica Acta, vol. 579, no. 2, pp. 185-192, 2006.

[16] K.-H. Bannefeld, H. Stass, and G. Blaschke, "Capillary electrophoresis with laser-induced fluorescence detection, an adequate alternative to high-performance liquid chromatography, for the determination of ciprofloxacin and its metabolite desethyleneciprofloxacin in human plasma," Journal of Chromatography B: Biomedical Sciences and Applications, vol. 692, no. 2, pp. 453-459, 1997.

[17] J. A. Murillo, A. Alañón Molina, A. Muñoz de la Peña, I. Durán Merás, and A. Jiménez Girón, "Resolution of ofloxacin-ciprofloxacin and ofloxacin-norfloxacin binary mixtures by flow-injection chemiluminescence in combination with partial least squares multivariate calibration," Journal of Fluorescence, vol. 17, no. 5, pp. 481-491, 2007.

[18] J. L. Beltrán, E. Jiménez-Lozano, D. Barbosa, and J. Parbosa, "Determination of quinolone antimicrobial agents in strongly overlapped peaks from capillary electrophoresis using multivariate calibration methods," Analytica Chimica Acta, vol. 501, no. 2, pp. 137-141, 2004.

[19] L. Coda and L. Timallo, "Determination of fluocinolone acetonide in a dermatologic cream using differential UV spectrophotometry," Bollettino Chimico Parmaceutico, vol. 115, no. 7, pp. 515-520, 1976.

[20] L. Amendola, F. Garribba, and F. Botrè, "Determination of endogenous and synthetic glucocorticoids in human urine by gas chromatography-mass spectrometry following microwave-assisted derivatization," Analytica Chimica Acta, vol. 489, no. 2, pp. 233-243, 2003.

[21] V. Giaccone, G. Polizzotto, A. Macaluso, G. Cammilleri, and V. Ferrantelli, "Determination of ten corticosteroids in illegal cosmetic products by a simple, rapid, and high-performance LC-MS/MS method," International Journal of Analytical Chemistry, vol. 2017, Article ID 3531649, 12 pages, 2017.

[22] V. Cirimele, P. Kintz, V. Dumestre, J. P. Goullé, and B. Ludes, "Identification of ten corticosteroids in human hair by liquid chromatography-ion spray mass spectrometry," Forensic Science International, vol. 107, no. 1-3, pp. 381-388, 2000.
[23] L. Gagliardi, D. De Orsi, M. R. D. Giudice et al., "Development of a tandem thin-layer chromatography-high-performance liquid chromatography method for the identification and determination of corticosteroids in cosmetic products," Analytica Chimica Acta, vol. 457, no. 2, pp. 187-198, 2002.

[24] P. Volin, "High-performance liquid chromatographic analysis of corticosteroids," Journal of Chromatography B, vol. 671, no. 1-2, pp. 319-340, 1995.

[25] K. Fluri, L. Rivier, A. Dienes-Nagy et al., "Method for confirmation of synthetic corticosteroids in doping urine samples by liquid chromatography-electrospray ionisation mass spectrometry," Journal of Chromatography A, vol. 926, no. 1, pp. 87-95, 2001.

[26] P. Srinivasu, D. V. SubbaRao, R. V. K. Vegesna, and K. S. Babu, "A validated stability-indicating LC method for fluocinonide in the presence of degradation products, its process-related impurities and identification of degradation products," American Journal of Analytical Chemistry, vol. 01, no. 03, pp. 113-126, 2010.

[27] A. Chmielewska, L. Konieczna, and H. Lamparczyk, "Development of a reversed-phase HPLC method for analysis of fluocinolone acetonide in gel and ointment," ActaChromatographica, vol. 16, pp. 80-91, 2006.

[28] R. H. Obaydo and A. Alhaj Sakur, "Spectrophotometric strategies for the analysis of binary combinations with minor component based on isoabsorptive point's leveling effect: an application on ciprofloxacin and fluocinolone acetonide in their recently delivered co-formulation," Spectrochimica Acta Part A: Molecular and Biomolecular Spectroscopy, vol. 219, pp. 186-194, 2019.

[29] H. M. Lotfy and Y. R. Omran, "Novel absorptivity centering method utilizing normalized and factorized spectra for analysis of mixtures with overlapping spectra in different matrices using built-in spectrophotometer software," Spectrochimica Acta Part A: Molecular and Biomolecular Spectroscopy, vol. 200, pp. 167-178, 2018.

[30] H. M. Lotfy and S. S. Saleh, "Investigating advanced approaches based on iso-absorptivity coefficient in unresolved spectral signals of binary mixtures," Journal of Analytical Methods in Chemistry, vol. 2019, Article ID 7924821, 10 pages, 2019.

[31] H. M. Lotfy, D. Mohamed, and M. S. Elshahed, "Novel univariate spectrophotometric determination of the recently released solid dosage form comprising dapagliflozin and saxagliptin via factorized response spectra: assessment of the average content and dosage unit uniformity of tablets," Spectrochimica Acta Part A: Molecular and Biomolecular Sectroscopy, vol. 222, article 117120, 2019.

[32] M. G. El-Bardicy, H. M. Lotfy, M. A. El-Sayed, and M. F. ElTarras, "Smart stability-indicating spectrophotometric methods for determination of binary mixtures without prior separation," Journal of AOAC International, vol. 91, no. 2, pp. 299-310, 2008.

[33] H. M. Lotfy, S. S. Saleh, N. Y. Hassan, and S. M. Elgizawy, "Univariate versus multivariate spectrophotometric methods for simultaneous determination of complex binary mixtures with overlapped spectra: a comparative study," Analytical Chemistry Letters, vol. 3, no. 2, pp. 70-84, 2013.

[34] M. R. Elghobashy, L. I. Bebawy, R. F. Shokry, and S. S. Abbas, "Successive ratio subtraction coupled with constant multiplication spectrophotometric method for determination of hydroquinone in complex mixture with its degradation products, tretinoin and methyl paraben," Spectrochimica Acta 
Part A: Molecular and Biomolecular Spectroscopy, vol. 157, pp. 116-123, 2016.

[35] H. M. Lotfy and M. Abdel-Monem Hagazy, "Comparative study of novel spectrophotometric methods manipulating ratio spectra: an application on pharmaceutical ternary mixture of omeprazole, tinidazole and clarithromycin," Spectrochimica Acta Part A: Molecular and Biomolecular Spectroscopy, vol. 96, pp. 259-270, 2012.

[36] H. M. Lotfy and M. A. M. Hegazy, "Simultaneous determination of some cholesterol-lowering drugs in their binary mixture by novel spectrophotometric methods," Spectrochimica Acta Part A: Molecular and Biomolecular Spectroscopy, vol. 113, pp. 107-114, 2013.

[37] H. M. Lotfy, M. A. Hegazy, M. R. Rezk, and Y. R. Omran, "Novel spectrophotometric methods for simultaneous determination of timolol and dorzolamide in their binary mixture," SpectrochimicaActa Part A: Molecular and Biomolecular Spectroscopy, vol. 126, pp. 197-207, 2014.

[38] H. M. Lotfy, S. M. Tawakkol, N. M. Fahmy, and M. A. Shehata, "Successive spectrophotometric resolution as a novel technique for the analysis of ternary mixtures of pharmaceuticals," Spectrochimica Acta Part A: Molecular and Biomolecular Spectroscopy, vol. 121, pp. 313-323, 2014.

[39] H. M. Lotfy and S. S. Saleh, "Testing the purity of spectral profiles: finger-print resolution of complex matrices and extraction of absorbance signals," Spectrochimica Acta Part A: Molecular and Biomolecular Spectroscopy, vol. 205, pp. 160$169,2018$.

[40] A. Samir, H. M. Lotfy, H. Salem, and M. Abdelkawy, "Development and validation of simultaneous spectrophotometric and TLC-spectrodensitometric methods for determination of beclomethasone dipropionate and salbutamol in combined dosage form," Spectrochimica Acta Part A: Molecular and Biomolecular Spectroscopy, vol. 128, pp. 127-136, 2014.

[41] E. H. Mohamed, H. M. Lotfy, M. A. Hegazy, and S. Mowaka, "Different applications of isosbestic points, normalized spectra and dual wavelength as powerful tools for resolution of multicomponent mixtures with severely overlapping spectra," Chemistry Central Journal, vol. 11, no. 1, 2017.

[42] Q2b Icohiqa, "Validation of analytical procedures: Methodology," Federal Register, vol. 62, no. 96, pp. 27463-27467, 1997.

[43] H. M. Lotfy, M. A. Hegazy, M. R. Rezk, Y. R. Omran, and Y. R. Omran, "Comparative study of novel versus conventional two-wavelength spectrophotometric methods for analysis of spectrally overlapping binary mixture," Spectrochimica Acta Part A: Molecular and Biomolecular Spectroscopy, vol. 148, pp. 328-337, 2015.

[44] H. E. Zaazaa, E. S. Elzanfaly, A. T. Soudi, and M. Y. Salem, "Spectrophotometric method for the determination of two coformulated drugs with highly different concentrations. Application on vildagliptin and metformin hydrochloride," Journal of Applied Spectroscopy, vol. 83, no. 1, pp. 137-140, 2016. 

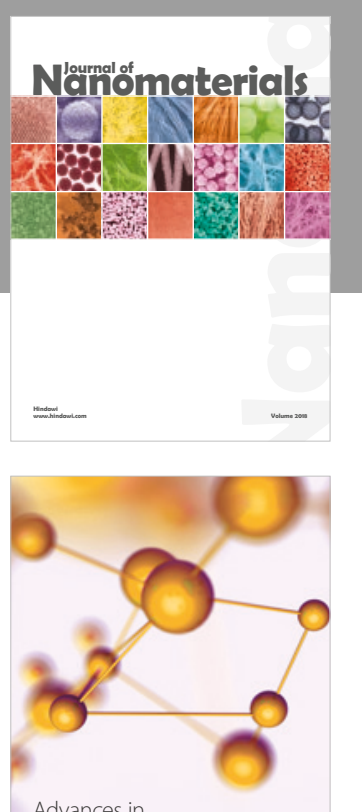

Physical Chemistry
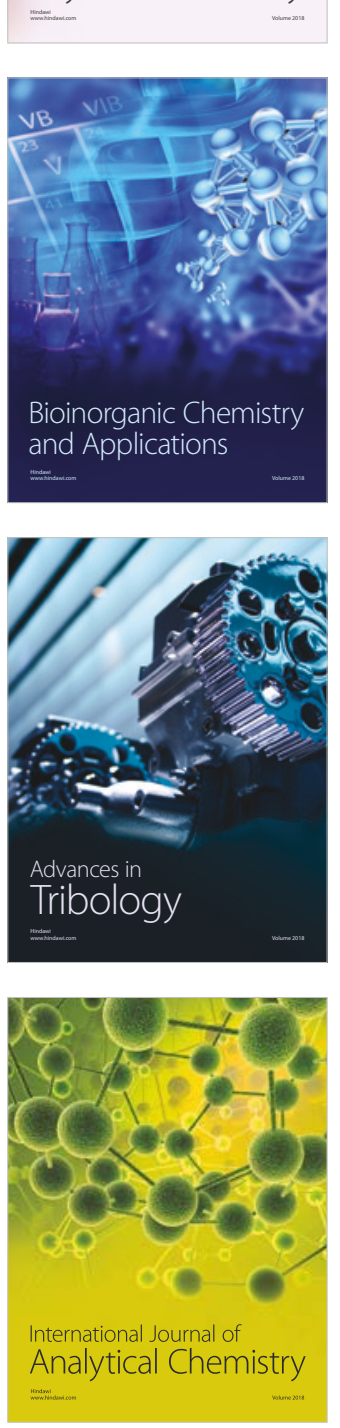

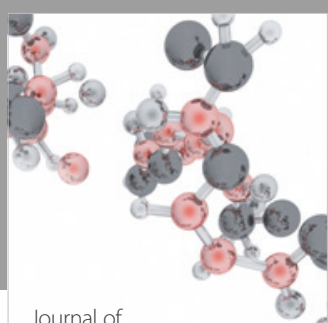

Analytical Methods

in Chemistry

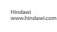

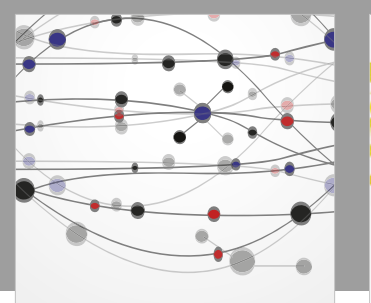

The Scientific World Journal

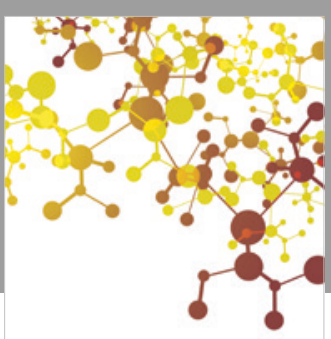

Journal of

Applied Chemistry
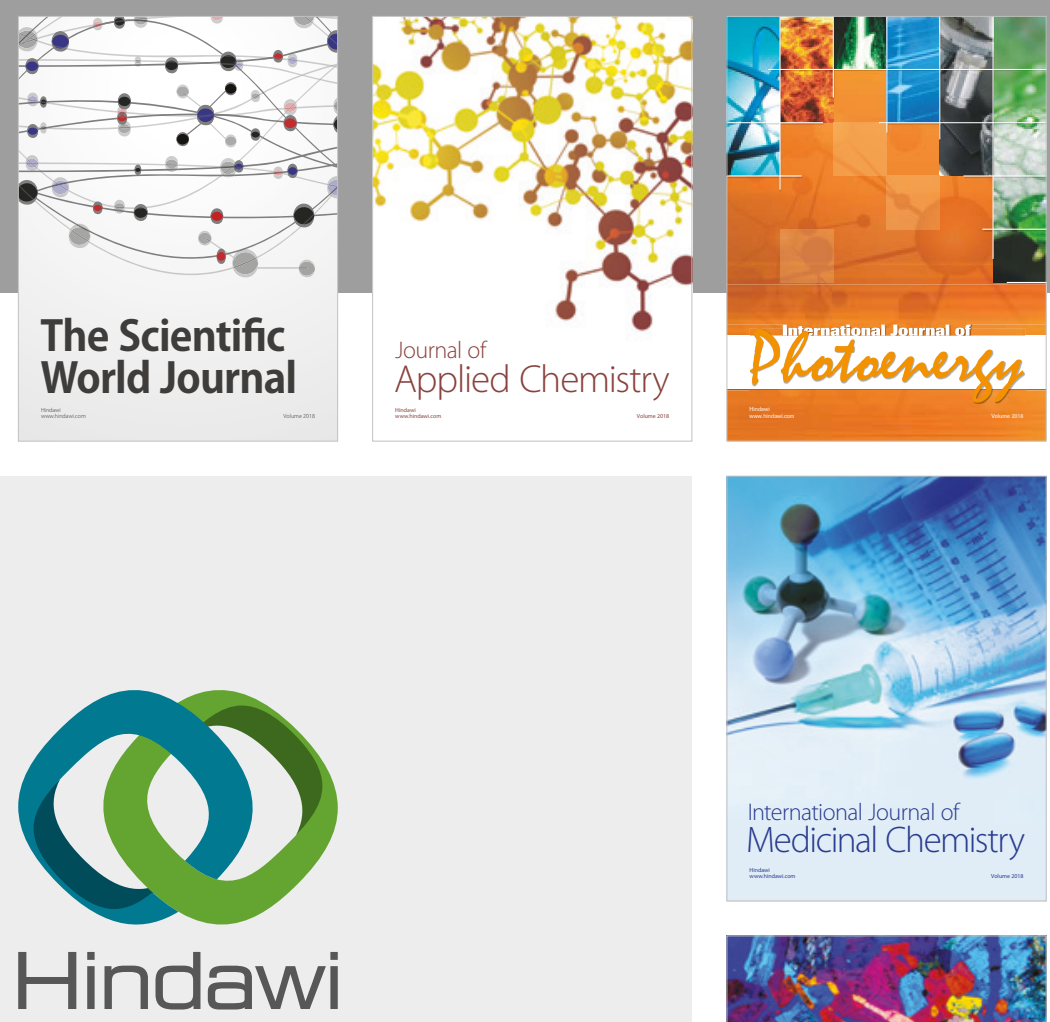

Submit your manuscripts at

www.hindawi.com
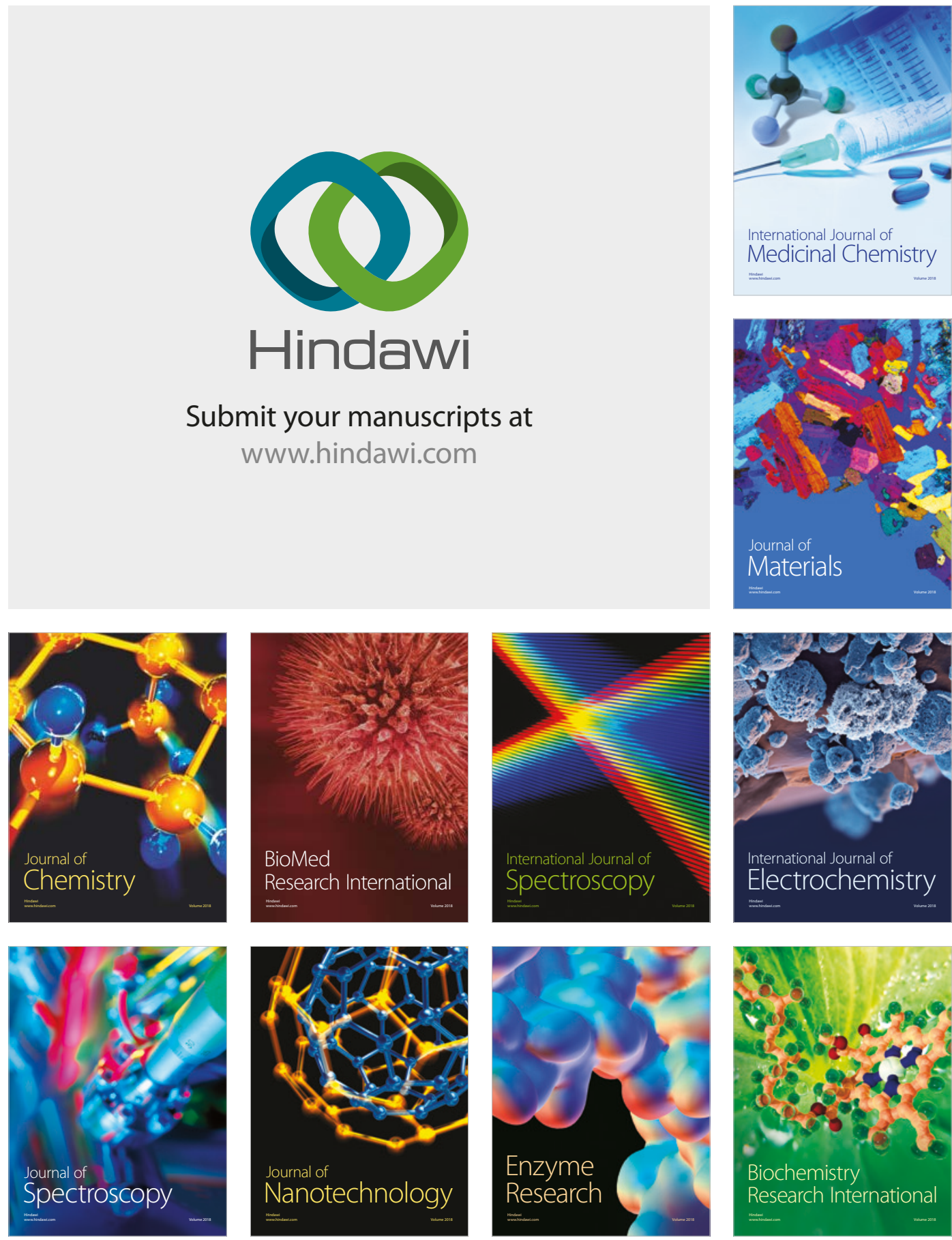
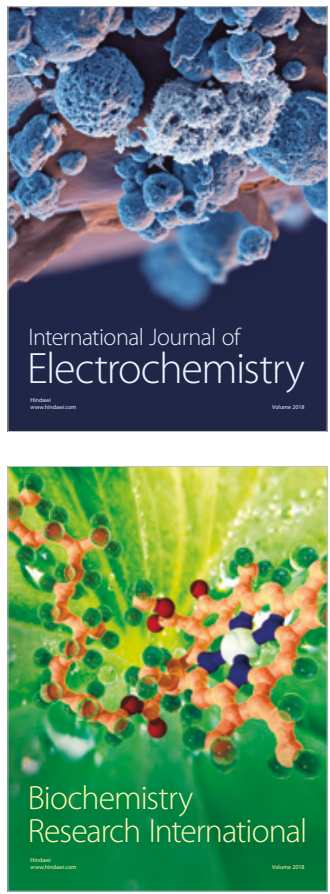